JEEP 2011, 00012 (2011)

DOI: $10.1051 /$ jeep/201100012

(C) Owned by the authors, published by EDP Sciences, 2011

\title{
Phenomenology of polymorphism and topological pressure-temperature diagrams: the case study acesulfame
}

\author{
I.B. Rietveld ${ }^{1 *}$, R. Céolin ${ }^{1}$, S. P. Velaga ${ }^{2}$, S. Basavoju ${ }^{2}$ \\ ${ }^{1}$ Laboratoire de Chimie Physique, EAD Physico-Chimie Industrielle du Médicament, Faculté de Pharmacie de \\ l’Université Paris Descartes, 75006 Paris, France \\ ${ }^{2}$ Department of Health Sciences, Luleå University of Technology, Luleå S-97187, Sweden \\ *ivo.rietveld@parisdescartes.fr
}

\begin{abstract}
The phase relationships involving the two known polymorphs of acesulfame have been determined from experimental data through topological arguments based on the Clapeyron equation. It is found that the resulting topological P-T diagram, in which the behavior of acesulfame form II becomes monotropic at higher pressure, resembles that the "paradigmatic" $\mathrm{S}_{8}$ dimorphism.
\end{abstract}

\section{Introduction}

The potassium salt of Acesulfame is widely used as a caloric-free sweatener. Acesulfame (Figure 1) exists in the solid state in the form of two polymorphic modifications whose crystal structures and thermal behavior have been reported [1].

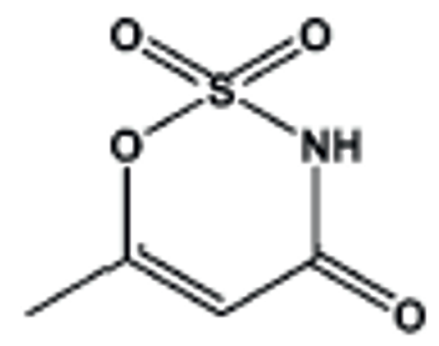

Fig. 1: Acesulfame chemical formula

\section{Experimental}

The data reported in ref.[1] are:

Monoclinic P $21 / \mathrm{c}$ form I melts at $395 \mathrm{~K}\left(\Delta_{\text {fus }} \mathrm{H}(\mathrm{I})=132.4\right.$

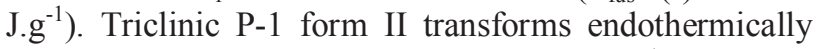
into form I at $356 \mathrm{~K}\left(\Delta_{\mathrm{II} \rightarrow \mathrm{I}} \mathrm{H}=+5.4 \mathrm{~J} . \mathrm{g}^{-1}\right)$. Specific volumes vs. T (Figure 2 ) determined from densities show that $\mathrm{v}(\mathrm{I})>\mathrm{v}(\mathrm{II})$.

$\mathrm{v}(\mathrm{I}) / \mathrm{cm}^{3} \mathrm{~g}^{-1}=0.5981+\left(7.0263 \times 10^{-5} \times \mathrm{T} / \mathrm{K}\right)$
$\mathrm{v}(\mathrm{II}) / \mathrm{cm}^{3} \mathrm{~g}^{-1}=0.5545+\left(1.0203 \times 10^{-4} \times \mathrm{T} / \mathrm{K}\right)$

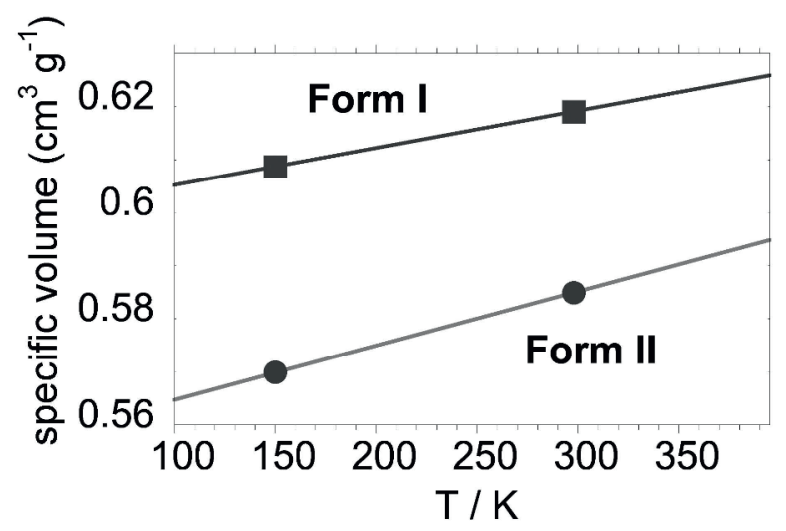

Fig. 2. Specific volumes of Acesulfame Forms I and II

\section{Results}

With these data, the slope of the P-T curve for transition II-I takes the value 4.7 $\mathrm{MPa}^{-1} \mathrm{~K}^{-1}$ using $\Delta_{\mathrm{II} \rightarrow \mathrm{I}} \mathrm{V}=0.0323$ $\mathrm{cm}^{3} \cdot \mathrm{g}^{-1}$ at $356 \mathrm{~K}$.

Assuming that $\Delta_{\text {fusI }} \mathrm{V}$ ranges within 1.05 to 1.10 times $\mathrm{v}(\mathrm{I})$ at $\mathrm{T}_{\text {fus }}(\mathrm{I})$, which appears to be a reasonable estimate $[2,3$, 4], the slope $\mathrm{dP} / \mathrm{dT}$ of the P-T curve for equilibrium Iliquid is found to be within 10.7 and $5.4 \mathrm{MPa}^{-1}$, i.e. greater than $\mathrm{dP} / \mathrm{dT}(\mathrm{II}-\mathrm{I})$. The I-II and I-liquid equilibrium curves should subsequently converge to triple point I-IIliquid, thus located at high pressure. 
It is to be kept in mind that the II-liquid equilibrium curve should pass through this triple point, with which it shares two common phases. In addition, taking into account the alternation rule, it should be inferred that the $\mathrm{dP} / \mathrm{dT}$ slope of the II-liquid equilibrium curve should be smaller than that of the I-liquid curve and greater than that of the I-II equilibrium curve.

Using calculated values for the (vapor) pressure of the liquid-vapor equilibrium curve [2], and assuming that the melting point of form I approximates triple point I-liquidvapor, the location of the II-liquid-vapor triple point can be estimated as follows (see Figure 3).

The vaporization enthalpy and the temperature of the boiling point of the melt are calculated with $\mathrm{ACD} / \mathrm{Labs}$ software [2]: $\Delta_{\text {vap }} \mathrm{H}=64.6 \mathrm{~kJ} . \mathrm{mol}^{-1}, \mathrm{~Tb}=590 \mathrm{~K}$.

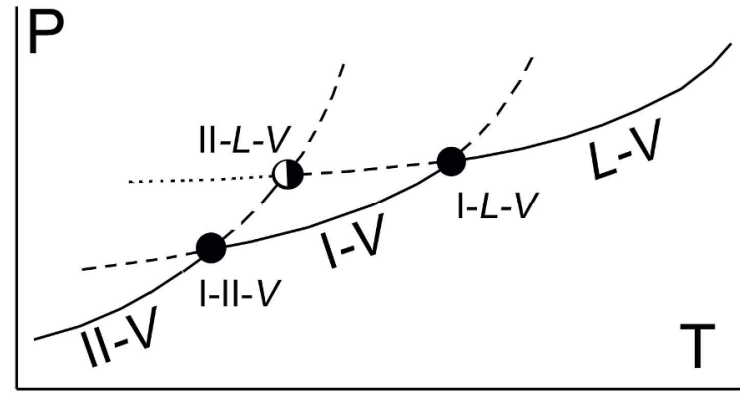

Fig. 3. Relative positions of triple points I- $L-V$, II- $L-V$ and I-II$V(L=$ liquid, $V=$ vapor $)$ and equilibrium curves involving the vapor phase. Filled circles: stable triple points, Half-filled circle: metastable triple point.

Assuming that $\Delta_{\text {vap }} \mathrm{H}, \quad \Delta_{\text {sub }} \mathrm{H}(\mathrm{I})$ and $\Delta_{\text {sub }} \mathrm{H}(\mathrm{II})$ are independent of $\mathrm{T}$, the vapor pressures of the condensed phases are calculated with

$\operatorname{LnP}=-(\Delta H / R \cdot T)+B$

Since $\mathrm{P}_{\text {vap }}=\mathrm{P}_{\text {sub }} \mathrm{I}$ at $\mathrm{T}(\mathrm{I}-L-V), \mathrm{P}_{\text {sub }} \mathrm{I}=\mathrm{P}_{\text {sub }} \mathrm{II}$ at T(I-II- $\left.V\right)$, $\Delta_{\text {sub }} \mathrm{H}(\mathrm{I})=\Delta_{\text {vap }} \mathrm{H}+\Delta_{\text {fus }} \mathrm{H}(\mathrm{I})$ and $\Delta_{\text {sub }} \mathrm{H}(\mathrm{II})=\Delta_{\text {sub }} \mathrm{H}(\mathrm{I})+$ $\Delta_{\mathrm{II} \rightarrow \mathrm{I}} \mathrm{H}$, the sublimation curves for forms I and II can be calculated. Then by equating $\mathrm{P}_{\text {sub }} \mathrm{II}$ and $\mathrm{P}_{\text {vap }}$, the temperature of triple point II- $L-V$, i.e. virtually the melting point of form II, is found to be lower by about 4 degrees than the melting temperature of form I.

Disregarding the real values for the coordinates of triple point I-II- $L$, the topology indicates that the thermal behavior of form II, which is enantiotropic at "ordinary" pressure, should become monotropic at higher pressure.

\section{Concluding remarks}

The present case of dimorphism is shown to be related to Roozeboom's case 1 (i.e. the "paradigmatic" diagram of dimorphic $\mathrm{S}_{8}$ ) of $\mathrm{P}-\mathrm{T}$ diagrams that illustrate the relationships involving two polymorphs. It may thus be concluded that the topological method connects thermal behavior of polymorphs to one of Roozeboom's four cases [5], by taking pressure into account.
Nevertheless, experimental studies are indispensable to verify topological inferences.

\section{References}

1. S. P. Velaga, V. R. Vangala, S. Basavoju and D. Boström, Chem. Comm., 46, 3562 (2010)

2. Advanced Chemistry Development, (ACD/Labs) Software

3. B. T. Goodman, W.V. Wilding, J. L. Oscarson and R. L. Rowley, J. Chem. Eng. Data, 49, 1512 (2004)

4. R. Céolin and I. B. Rietveld, J. Therm. Anal. Calorim., 102, 357 (2010)

5. H. W. Bakhuis Roozeboom. Die heterogenen Gleichgewichte vom Standpunkte der Phasenlehre. Erstes Heft: Die Phasenlehre: Systeme aus einer Komponente. p.183-189. Vieweg, Braunschweig, (1901) 